\title{
Knockdown of long non-coding RNA CCAT2 suppresses the progression of thyroid cancer by inhibiting the Wnt/B-catenin pathway
}

\author{
SUPING XIN and XINHUA YE \\ Department of Endocrinology, Changzhou Second People's Hospital Affiliated to Nanjing Medical University, \\ Changzhou, Jiangsu 213000, P.R. China
}

Received January 20, 2020; Accepted September 4, 2020

DOI: $10.3892 /$ ijmm.2020.4761

\begin{abstract}
Thyroid cancer (TC) is one of the most common malignancies with a high mortality rate. Long non-coding RNA CCAT2 (CCAT2) participates in the occurrence and development of certain human cancers; however, whether it is involved in TC remains unclear. Thus, the present study investigated the role of CCAT2 in TC and the underlying mechanism. CCAT2 expression in both TC tissues and cell lines was examined by reverse transcription-quantitative PCR. CCAT2 expression was silenced in TC cell lines by a specific small interfering (si)RNA against CCAT2 (si-CCAT2). The effects of CCAT2 silencing on TC cell proliferation were detected by CCK- 8 and colony formation assays. Cell cycle and apoptosis of the treated TC cells were assessed by flow cytometry. Wound healing and Transwell assays were performed to detect the effects of si-CCAT2 on the migration and invasion of TC cells. Apoptosis-related proteins and Wnt/ $\beta$-catenin cascade-associated agents were examined by western blotting. The interaction between CCAT2 and the Wnt/ $\beta$-catenin pathway in the transfected cells was detected by performing a dual-luciferase reporter assay. CCAT2 expression was increased in TC tissue samples and cell lines compared with the controls. Tissue CCAT2 level was associated with $\mathrm{T}$ stage and tumor-node-metastasis stage of TC. Silencing CCAT2 inhibited TC cell proliferation, migration
\end{abstract}

Correspondence to: Dr Xinhua Ye, Department of Endocrinology, Changzhou Second People's Hospital Affiliated to Nanjing Medical University, 29 Xinglong Alley, Tianning, Changzhou, Jiangsu 213000, P.R. China

E-mail: yexh_xinhuay@163.com

Abbreviations: TC, thyroid cancer; FTC, follicular thyroid cancer; PTC, papillary thyroid cancer; ATC, anaplastic thyroid cancer; lncRNA, long non-coding RNA; RT-qPCR, reverse transcription-quantitative PCR; PI, propidium iodide; LEF, lymphoid enhancer binding factor; TCF, transcription factor

Key words: thyroid cancer, CCAT2, Wnt/ $\beta$-catenin signaling pathway, proliferation, migration, invasion and invasion, and promoted TC cell cycle arrest and apoptosis. Furthermore, CCAT2 knockdown suppressed the activity of the $\mathrm{Wnt} / \beta$-catenin cascade in TC cells treated with lithium chloride. In summary, the present study demonstrated that CCAT2 knockdown suppresses TC progression via inactivating the $\mathrm{Wnt} / \beta$-catenin cascade, indicating that suppressing CCAT2 and the Wnt/ $\beta$-catenin signaling pathway may be a promising therapeutic strategy for treating TC.

\section{Introduction}

Thyroid cancer (TC) is one of the most common malignancies worldwide (1). The incidence of TC is steadily increasing in some regions and nations including those in South and North America, Italy, Japan and the Pacific Islands (2). An estimation from the American Cancer Society stated that $\sim 52,070$ new TC cases were diagnosed in 2019 in the USA, resulting in $>2,170$ TC-associated mortalities (3). A study involving 255 patients reported that the incidence of TC is $\sim 10.58 / 100,000$ in China (4). TC can be divided into the four following subtypes according to its histopathological characteristics: i) Papillary thyroid cancer (PTC); ii) follicular thyroid cancer (FTC); iii) poorly differentiated thyroid cancer; and iv) anaplastic thyroid cancer (ATC) (5-7). Among these subtypes, PTC is the most frequently diagnosed type of TC, accounting for $\sim 85 \%$ of all TC cases, and ATC is the most aggressive type of TC, with a poor prognosis (8). Therefore, investigating the underlying molecular mechanisms of TC pathogenesis for the development of novel effective diagnostic and therapeutic targets is needed.

Long non-coding RNAs (IncRNAs) are a type of RNA molecule with $>200$ nucleotides but which do not have protein-encoding ability (9). LncRNAs are located in the nucleus and are more tissue-specific compared with mRNAs (10). TC is closely associated with aberrant expression profiles of lncRNAs (11). LncRNAs are implicated in tumor occurrence and development (12). Certain IncRNAs have been identified to play an important role in TC tumorigenesis, such as taurine up-regulated gene $1, \mathrm{X}$-inactive specific transcript and metastasis associated lung adenocarcinoma transcript 1 (11). LncRNAs regulate the expression and function of their target genes through multiple mechanisms by acting as miRNAs sponges, molecular scaffolds or protein decoys (13). 
LncRNA CCAT2 (CCAT2) has previously been reported to be involved in the tumor progression of multiple human tumors, such as colorectal cancer, osteosarcoma and pituitary adenomas (14-16). However, to the best of our knowledge, the role of CCAT2 in TC has not been investigated. The present study aimed to investigate whether CCAT2 plays a role in TC, hoping to provide an improved understanding of the complex pathogenesis of TC and promote the development of therapeutic targets.

\section{Materials and methods}

Collection of TC tissue samples and cell culture. TC tissue samples and adjacent normal tissue samples (30 pairs containing 17 papillary, 9 follicular, and 4 anaplastic) were collected from 30 patients who underwent thyroidectomy at The Changzhou Second People's Hospital Affiliated to Nanjing Medical University (Changzhou, China) between 2013 October and 2018 October, including 8 male patients and 22 female patients. The age range of the patients was $37-60$ years, with a mean age of 43 years. The adjacent normal tissue was $\sim 2 \mathrm{~cm}$ away from TC tissue samples. All patients did not receive preoperative radiotherapy or chemotherapy prior to the study. Benign or malignant thyroid nodules were diagnosed based on pathological features by the pathologists as aspiration of thyroid nodules was used for primary diagnosis on TC, which was confirmed in a previous study (17). Patients with TC were divided into the high-CCAT2 group and low-CCAT2 group according to the median level of tissue CCAT 2 ( $n=15$ per group). Tumor stages were determined based on the tumor-node-metastasis (TNM) criteria of the American Joint Committee on Cancer classification (8th edition) (18). Written informed consent was obtained from all the patients, and this study was approved by the Ethics Committee of the Changzhou Second People's Hospital Affiliated to Nanjing Medical University (approval no. NK2013100101).

The human thyroid follicular epithelial cell line (Nthy-ori3-1) and the TC cell lines (TPC-1, HTH83, IHH4, FTC-133 and FTC-238) were all obtained from the Chinese Academy of Medical Sciences (Shanghai, China), which included three PTC cell lines (TPC-1, HTH83 and IHH4) and two FTC cell lines (FTC-133 and FTC-238). The cells were cultured in RPMI-1640 medium (Gibco; Thermo Fisher Scientific, Inc.), which was supplemented with $10 \%$ fetal bovine serum (Gibco; Thermo Fisher Scientific, Inc.) and $1 \%$ penicillin/streptomycin (Gibco; Thermo Fisher Scientific, Inc.), and maintained in cell incubators at $37^{\circ} \mathrm{C}$ with $5 \% \mathrm{CO}_{2}$.

Reverse transcription-quantitative PCR (RT-qPCR) assay. RNA was extracted from TC tissues and cells using TRIzol reagent (Invitrogen; Thermo Fisher Scientific, Inc.). cDNAs were synthesized using a BestarTM qPCR RT kit (DBI Bioscience) according to the manufacturer's protocol. qPCR was conducted in an ABI 7500 system (ABI Biosystems) using a SYBR-Green kit (Bio-Rad Laboratories, Inc.) and a 20- $\mu 1$ reaction mixture containing $0.3 \mu \mathrm{l} \mathrm{cDNA}$ and $0.4 \mu \mathrm{M}$ primers. The amplification conditions were as follows: $5 \mathrm{~min}$ at $95^{\circ} \mathrm{C}$, 35 cycles of $35 \mathrm{sec}$ at $95^{\circ} \mathrm{C}, 50 \mathrm{sec}$ at $60^{\circ} \mathrm{C}, 20 \mathrm{sec}$ at $72^{\circ} \mathrm{C}$ and $2 \mathrm{~min}$ at $72^{\circ} \mathrm{C}$. Relative gene expression was calculated using the $2^{-\Delta \Delta \mathrm{Cq}}$ method (19), and GAPDH was used as the reference gene. The sequences of the primers used in the study were as follows: CCAT2 forward, 5'-CTTCCAGCTCCACCTCTG AC-3' and reverse, 5'-GAGCTCAAAGGACGATGAGG-3'; and GAPDH forward, 5'-GCACCGTCAAGGCTGAGAAC-3' and reverse, 5'-TGGTGAAGACGCCAGTGGA-3'.

CCAT2 silencing in TC cells. Since TPC-1 and FTC-133 cells exhibited a higher CCAT2 expression compared with the other TC cells, they were used for subsequent studies. To silence CCAT2 expression in TC cells, a specific small interfering (si)RNA against CCAT2 (si-CCAT2) and a negative control (si-NC) were purchased from Sangon Biotechnology Co., Ltd. After culturing the cells in 24 -well plates at $37^{\circ} \mathrm{C}$ for $24 \mathrm{~h}$, the TC cells $\left(1 \times 10^{5}\right.$ cells/well) were transfected with si-CCAT2 (50 nmol) or si-NC (50 nmol) using Lipofectamine 3000 (Invitrogen; Thermo Fisher Scientific, Inc.) according to the manufacturer's protocol. Following transfection for $\geq 24 \mathrm{~h}$, the CCAT2-silenced TC cells were used for further study. Knockdown efficiency of si-CCAT2 in TC cells was detected by RT-qPCR. The sequences used were as follows: si-CCAT2 sense, 5'-AAGUCCACCUGAUCACCUCGG-3' and antisense, 5'-GAGGUGAUCAGGUGGACUUUC-3'; and si-NC sense, 5'-AUAAGUCACCUCCACCUGCGG-3' and antisense, 5'-GCUUGAGAAGGGUGAUCUGUC-3'.

CCK- 8 assay. The TC cells transfected with si-NC or si-CCAT2 were separately seeded into 96 -well plates at a density of $1 \times 10^{5}$ cells/well and maintained at $37^{\circ} \mathrm{C}$ overnight. CCK-8 solution $(10 \mu \mathrm{l})$ was then added into each well and incubated with the cells for $10 \mathrm{~min}$. The absorbance of each well at $450 \mathrm{~nm}$ was detected using a microplate reader at the indicated time points $(24,48$ and $72 \mathrm{~h}$ post-cell culture).

Colony formation assay. The TC cells were collected and re-seeded into 6-well plates at a concentration of 3,000 cells/well following the transfection with si-NC or si-CCAT2 for $48 \mathrm{~h}$. After culture at $37^{\circ} \mathrm{C}$ under $5 \% \mathrm{CO}_{2}$ for 2 weeks, the cell colonies were stained with Giemsa solution at room temperature for $30 \mathrm{~min}$, and the visual colonies were counted under a stereo microscope (SZX10; Olympus Corporation) at x10 magnification.

Cell cycle analysis. After transfection for $48 \mathrm{~h}$, the TC cells were harvested and washed using PBS three times, and then fixed in pre-cold $70 \%$ ethanol at $4^{\circ} \mathrm{C}$ overnight. For analyzing the cell cycle, the fixed TC cells were subjected to propidium iodide (PI) staining at room temperature for $20 \mathrm{~min}$ in the dark. Cell cycle was analyzed using a FACSCalibur cytometer (Becton-Dickinson and Company) and FlowJo software (version 10; FlowJo, LLC).

Cell apoptosis analysis. For cell apoptosis analysis, the fixed TC cells were stained with PI (5 $\mu$; ; Sigma-Aldrich; Merck KGaA; cat. no. 81845) and Annexin V-FITC (5 $\mu \mathrm{l}$; BD Biosciences; cat. no. 556420) at room temperature for $30 \mathrm{~min}$, and the cell apoptosis was analyzed using a FACSCalibur cytometer (Becton-Dickinson and Company) and FlowJo software (version 10; FlowJo, LLC).

Western blot analysis. Whole cell extracts were collected using RIPA cell lysis buffer (Beyotime Institute of Biotechnology) with 
$1 \mathrm{mM}$ PMSF. Total proteins of the treated TC cells were extracted, and the protein concentration was determined using Bradford kit (Beijing Solarbio Science \& Technology, Inc.) and quantified using densitometry. The NE-PER Nuclear and Cytoplasmic Extraction Reagent kit (Pierce; Thermo Fisher Scientific, Inc.) was used for the extraction of cytoplasmic and nuclear proteins from the treated TC cells. Total proteins (50 $\mu \mathrm{g} / \mathrm{lane})$ were loaded and isolated using $10 \%$ SDS-PAGE, and then the target proteins were transferred to polyvinylidene difluoride (PVDF) membranes (EMD Millipore). Next, the PVDF membranes were immersed in 5\% non-fat milk at room temperature for $2 \mathrm{~h}$. The membranes were then probed with the following specific primary antibodies overnight at $4^{\circ} \mathrm{C}$ : Bcl-2 (cat. no. ab59348, 1:1,000), Bax (cat. no. ab32503, 1:1,000), cleaved (C)-caspase-3 (cat. no. ab2302, 1:1,000), $\beta$-catenin (cat. no. ab68183, 1:2,000), c-Myc (cat. no. ab39688, 1:1,000), Cyclin D1 (cat. no. ab134175, 1:10,000), Histon3 (cat. no. ab1791, 1:1,000) and GAPDH (cat. no. ab8245, 1:2,000). Histon3 and GAPDH were used as the internal controls. After washing the membranes with PBS three times, the membranes were incubated with horseradish peroxidase-conjugated secondary antibodies, including goat anti-rabbit IgG H\&L (cat. no. ab205718; 1:2,000) and goat anti-mouse IgG H\&L (cat. no. ab205719; 1:2,000), at room temperature for $1 \mathrm{~h}$. All the primary and secondary antibodies were purchased from Abcam. The signals were visualized using a ECL detection reagent (Amersham Biosciences). The blots were analyzed with an iBright CL750 Imaging System (cat. no. A441161 Thermo Fisher Scientific, Inc.) and grey values were calculated using ImageJ 5.0 (National Institute of Health).

Wound healing assay. The transfected TC cells were seeded into 6-well plates and allowed to grow to $100 \%$ confluence at $37^{\circ} \mathrm{C}$. Then, a $2-\mathrm{mm}$ wide wound was created on the cell surface using a sterile plastic scriber. The cells were then cultured in serum-free medium. The width of the wounds was observed using an inverted optical microscope (DP27; Olympus Corporation; magnification, x100) at 0 and $48 \mathrm{~h}$, and then measured using Image-Pro Plus Analysis software (version 6.0; Media Cybernetics, Inc.).

Transwell assay. Transwell chambers (Corning, Inc.) with $8-\mu \mathrm{m}$ pores were used to detect the effects of CCAT2 knockdown on TC cell invasion. The upper chamber was pre-coated with Matrigel at $37^{\circ} \mathrm{C}$ for $30 \mathrm{~min}$. The TC cells stably transfected with si-NC or si-CCAT2 were harvested and re-suspended in serum-free culture medium at a final concentration of $2 \times 10^{5}$ cells $/ \mathrm{ml}$. Subsequently, $200 \mu \mathrm{l}$ TC cell suspension was added to the upper chamber, while $500 \mu 1$ culture medium with $10 \%$ FBS was added to the lower chamber. Following culture for $48 \mathrm{~h}$, the non-invasive cells were removed, while the invaded TC cells were fixed in $4 \%$ paraformaldehyde and stained by crystal violet at room temperature for $20 \mathrm{~min}$. The invaded cells were counted under an inverted optical microscope (DP27; Olympus Corporation) at x200 magnification.

Wnt/ $\beta$-catenin pathway activity assessment. The effects of si-CCAT2 on the activity of the $\mathrm{Wnt} / \beta$-catenin cascade were assessed by a TCF/LEF Reporter kit (cat. no. 60500, BPS Bioscience, Inc.). In brief, the TC cells were seeded into 96-well plates at a concentration of $1 \times 10^{5}$ cells/well, cultured overnight and then transfected with $50 \mathrm{ng} \mathrm{LEF} / \mathrm{TCF}$ reporter plasmid. The LEF/TCF reporter-containing TC cells were then treated with $\mathrm{LiCl}$ or $\mathrm{LiCl}+$ si-CCAT2 (the concentration of $\mathrm{LiCl}$ was set at $10 \mathrm{mM}$ ) at $37^{\circ} \mathrm{C}$ for $48 \mathrm{~h}$, and the Wnt pathway activity was determined by a Dual-Luciferase Assay System (cat. no. E1910; Promega Corporation).

Statistical analysis. The data in the present study are shown as the mean \pm standard error of the mean. Statistical analysis for patients was performed using a Student's paired t-test, while other analyses were performed using one-way ANOVA followed by Tukey's post hoc test. Associations between CCAT2 expression and patient characteristics were analyzed using Fisher's exact test. GraphPad (version 7; GraphPad Software, Inc.) was used for analyses. $\mathrm{P}<0.05$ was considered to indicate a statistically significant difference.

\section{Results}

CCAT2 expression is increased in TC. To investigate whether CCAT2 is associated with TC, its expression in 30 paired tissue specimens collected from patients with TC was detected by RT-qPCR. Compared with the normal tissue samples, the expression of CCAT2 was significantly higher in the TC samples (Fig. 1A). Consistently, a significantly higher level of CCAT2 was observed in five TC cell lines (TPC-1, HTH83, IHH4, FTC-133 and FTC-238) compared with the Nthy-ori3-1 cell line (Fig. 1B). In addition, the association between tissue CCAT2 level and clinicopathological characteristics of TC patients were analyzed by Fisher's exact test. Patients with TC were divided into the high-CCAT2 group and low-CCAT2 group according to the median level of tissue CCAT2. No significant associations between tissue CCAT2 level and age, sex, tumor size, T stage, extrathyoridal extension or lymph node metastasis were observed. However, tissue CCAT2 level was significantly associated with TNM stage (Table I). In summary, CCAT2 may participate in the progression of TC.

CCAT2 silencing suppresses TC cell proliferation. Next, the expression of CCAT2 was silenced in TPC-1 and FTC-133 cells by a specific siRNA (si-CCAT2) and the cell viability and colony forming ability were examined. Knockdown efficiency of si-CCAT2 was evaluated by RT-qPCR. After transfection for $48 \mathrm{~h}$, the relative CCAT2 expression was significantly lower in the si-CCAT2-treated TPC-1 and FTC-133 cells compared with the blank and si-NC groups (Fig. 2A and B). CCK-8 assay demonstrated that at 24,48 and 72 h post-CCAT2 knockdown, the cell viabilities of TPC-1 and FTC-133 cells were significantly reduced compared with the blank and si-NC groups (Fig. 2C and D). To further investigate the long-term inhibitory effects of CCAT2-knockdown on TC cells, a colony formation assay was performed. The results indicated that knockdown of CCAT2 significantly inhibited the colony formation of TC cells compared with the blank and si-NC groups (Fig. 2E and F). Collectively, these findings suggested that CCAT2-knockdown inhibited TC cell viability in vitro.

CCAT2 silencing promotes TC cell cycle arrest and apoptosis. Subsequently, the effects of CCAT2 silencing on TC cell cycle and apoptosis were analyzed by flow cytometry. It was 
Table I. Clinicopathological characteristics of patients with thyroid cancer $(n=30)$.

\begin{tabular}{|c|c|c|c|c|}
\hline \multirow[b]{2}{*}{ Characteristic } & \multirow[b]{2}{*}{ Total, $\mathrm{n}$} & \multicolumn{2}{|c|}{ IncRNA CCAT2 expression } & \multirow[b]{2}{*}{ P-value } \\
\hline & & Low, n (\%) & High, n (\%) & \\
\hline \multicolumn{5}{|l|}{ Age, years } \\
\hline$<45$ & 18 & $10(55.56)$ & $8(44.44)$ & \multirow[t]{2}{*}{0.710} \\
\hline$\geq 45$ & 12 & $5(41.67)$ & $7(58.33)$ & \\
\hline \multicolumn{5}{|l|}{ Sex } \\
\hline Male & 8 & $3(37.50)$ & $5(62.50)$ & \multirow[t]{2}{*}{0.682} \\
\hline Female & 22 & $12(54.55)$ & $10(45.45)$ & \\
\hline \multicolumn{5}{|l|}{ Tumor size, $\mathrm{cm}$} \\
\hline$<2$ & 17 & $10(58.82)$ & $7(41.18)$ & \multirow[t]{2}{*}{0.462} \\
\hline$\geq 2$ & 13 & $5(38.46)$ & $8(61.54)$ & \\
\hline \multicolumn{5}{|l|}{ T stage } \\
\hline $\mathrm{T} 1-\mathrm{T} 2$ & 21 & $13(61.90)$ & $8(38.10)$ & \multirow[t]{2}{*}{0.109} \\
\hline $\mathrm{T} 3-\mathrm{T} 4$ & 9 & $2(22.22)$ & $7(77.78)$ & \\
\hline \multicolumn{5}{|l|}{ TNM stage } \\
\hline $\mathrm{I} / \mathrm{II}$ & 22 & $14(63.64)$ & $8(36.36)$ & \multirow[t]{2}{*}{$0.035^{\mathrm{a}}$} \\
\hline III/IV & 8 & $1(12.50)$ & $7(87.50)$ & \\
\hline \multicolumn{5}{|c|}{ Extrathyroidal extension } \\
\hline Yes & 16 & $7(43.75)$ & $9(56.25)$ & \multirow[t]{2}{*}{0.715} \\
\hline No & 14 & $8(57.14)$ & $6(42.86)$ & \\
\hline \multicolumn{5}{|c|}{ Lymph node metastasis } \\
\hline N0 & 18 & $11(61.11)$ & $7(38.89)$ & \multirow[t]{2}{*}{0.264} \\
\hline $\mathrm{N} 1$ & 12 & $4(33.33)$ & $8(66.67)$ & \\
\hline
\end{tabular}

${ }^{a} \mathrm{P}<0.05$. All data were analyzed using Fisher's exact test.
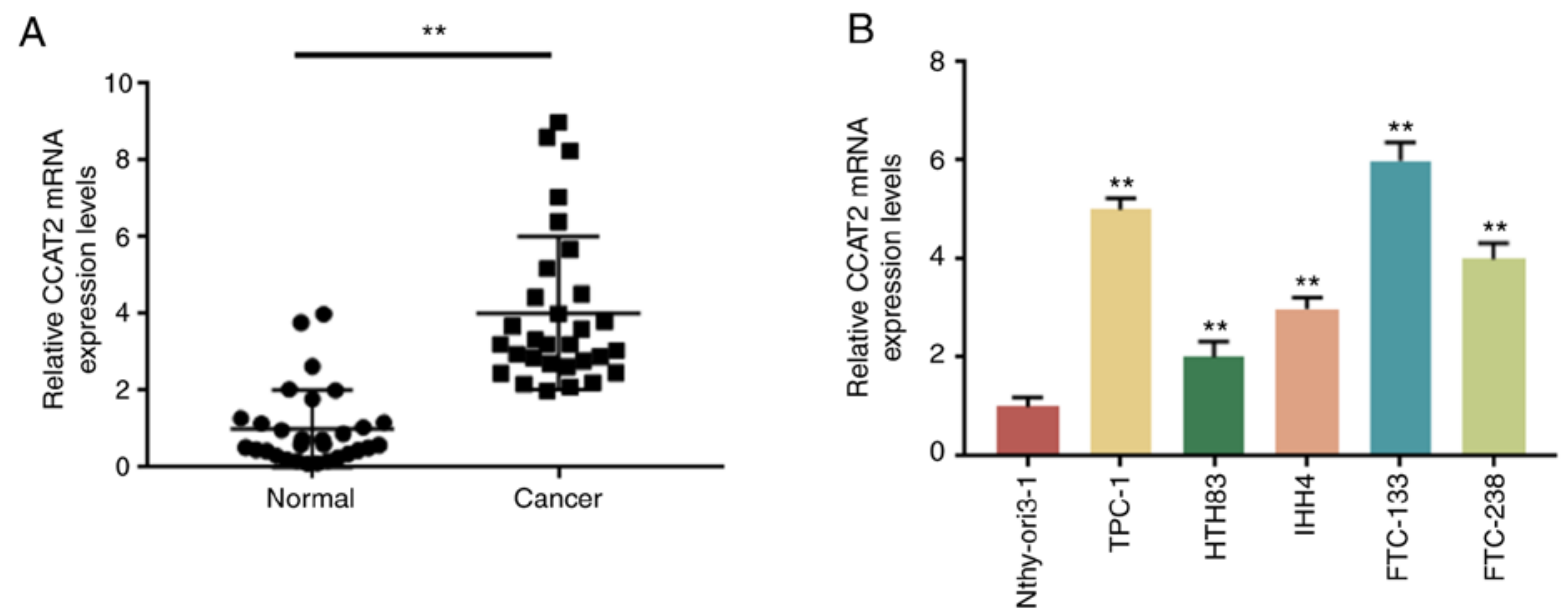

Figure 1. CCAT2 expression is increased in TC. (A) CCAT2 expression was assessed in TC tissues by reverse transcription-quantitative PCR. ${ }^{* *} \mathrm{P}<0.01$. (B) Relative expression of CCAT2 in the human thyroid follicular epithelial cell line (Nthy-ori3-1) and the TC cell lines (TPC-1, HTH83, IHH4, FTC-133 and FTC-238). ${ }^{* *} \mathrm{P}<0.01$ vs. Nthy-ori3-1 cells. TC, thyroid cancer.

identified that CCAT2 suppression significantly increased the apoptosis rate of TPC-1 and FTC-133 cells (Fig. 3A and B). Moreover, CCAT2 knockdown in TPC-1 and FTC-133 cells significantly increased the percentage of cells in the G1 phase and significantly reduced the percentage of cells in the $S$ phase (Fig. 3C and D), indicating that the cell cycle of TC cells was arrested at the G1 phase in the si-CACT2 group. In addition, the protein expression levels of Bcl-2, Bax and C-caspase- 3 in TPC-1 and FTC-133 cells of the blank, si-NC and si-CCAT2 groups were analyzed by western blotting. Compared with the blank and si-NC groups, si-CCAT2 significantly reduced Bcl-2 expression and significantly increased Bax and C-caspase-3 

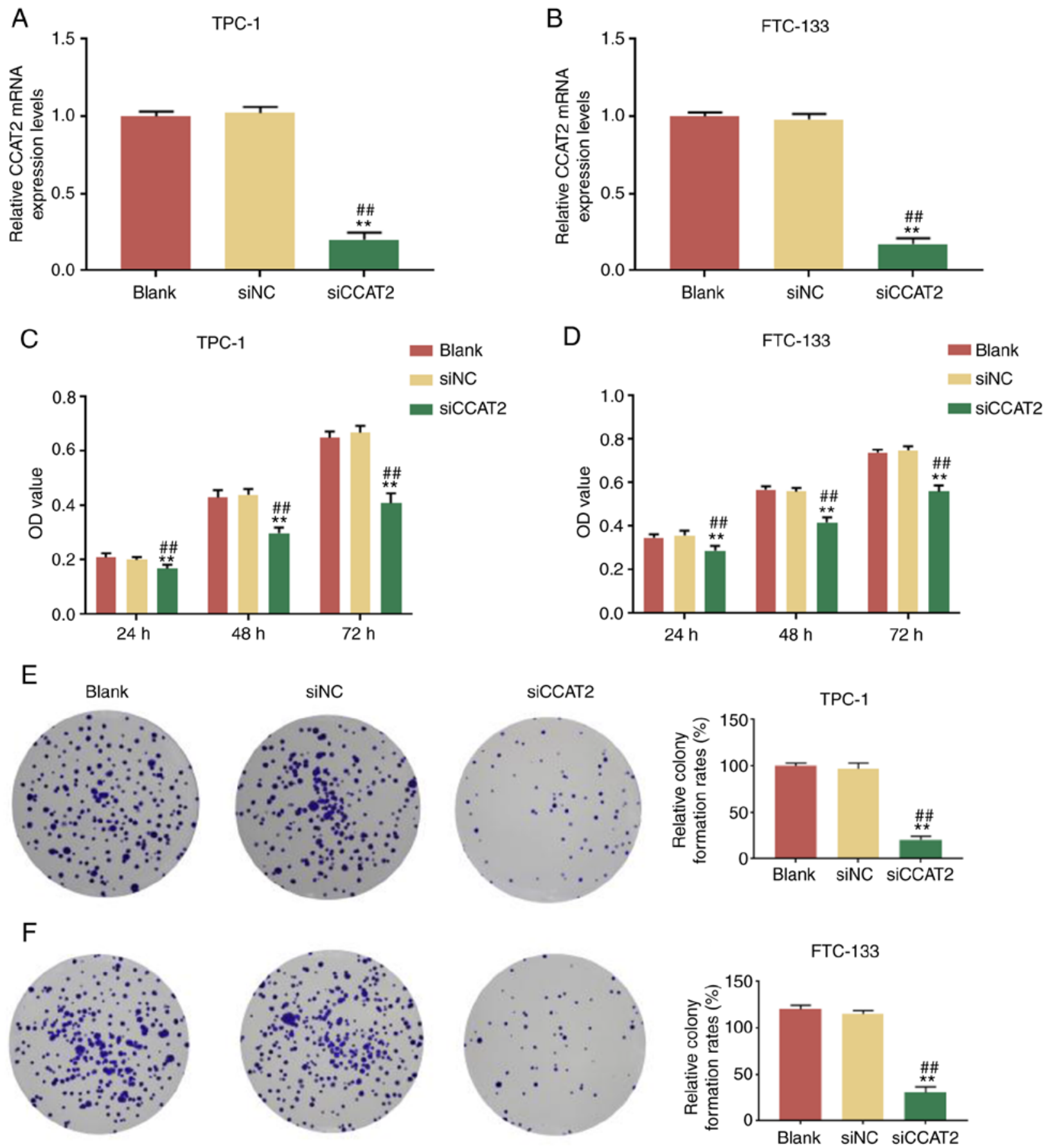

Figure 2. CCAT2 silencing suppresses thyroid cancer cell viability and colony formation. Relative CCAT2 expression in (A) TPC-1 and (B) FTC-133 cells in the blank, si-NC and si-CCAT2 groups. Cell viability of blank, si-NC and si-CCAT2 treated (C) TPC-1 and (D) FTC-133 cells was determined by CCK-8 assay. CCAT2 knockdown reduced the number of colonies formed in the (E) TPC-1 and (F) FTC-133 cells. Magnification, $x 5$. ${ }^{* *} \mathrm{P}<0.01 \mathrm{vs}$. blank; ${ }^{* \#} \mathrm{P}<0.01 \mathrm{vs}$. si-NC. si, small interfering RNA; NC, negative control; OD, optical density.

expression in both TPC-1 (Fig. 3E and F) and FTC-133 cells (Fig. 3G and H). These findings indicated that CCAT2 knockdown promoted cell apoptosis and cell cycle arrest of the TC cells.

CCAT2 silencing suppresses TC cell migration and invasion. The effects of CCAT2 silencing on the cell migration and invasion of TPC-1 and FTC-133 cells were subsequently evaluated by wound healing and Transwell assays. Wound healing assay demonstrated that the migration of TPC-1 and FTC-133 cells transfected with si-CCAT2 was significantly attenuated compared with the cells in the blank and si-NC groups (Fig. 4A and B). Furthermore, Transwell assay revealed that the invasion of TPC-1 and FTC-133 cells was also significantly suppressed by si-CCAT2 compared with the si-NC treatment and blank groups (Fig. 4C and D). These results indicated that CCAT2 silencing suppressed the migration and invasion of TC cells.

CCAT2 silencing inhibits Wnt/ $\beta$-catenin activity of TC cells. The Wnt $/ \beta$-catenin cascade is implicated in the proliferation, apoptosis, differentiation and invasion of tumor cells (20). 
A

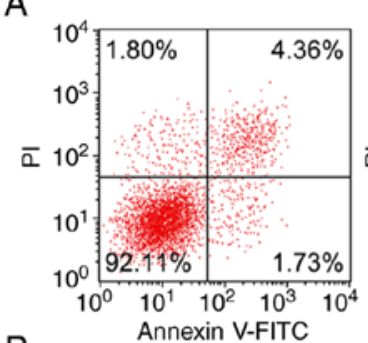

B

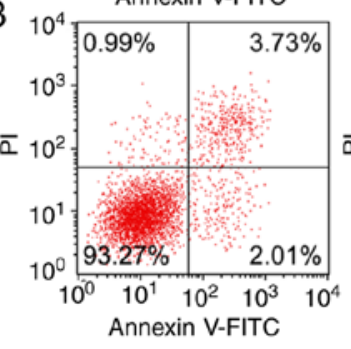

C
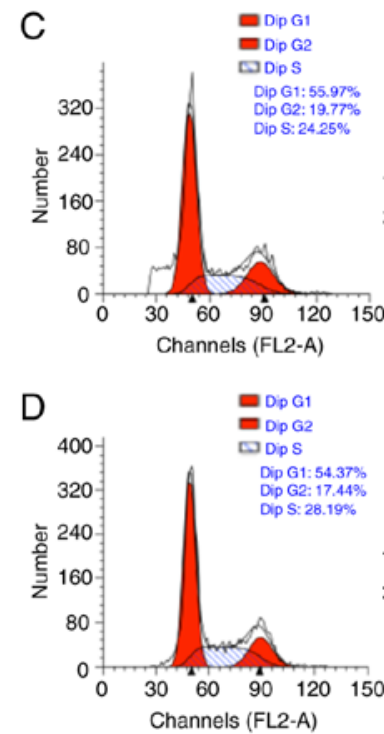

E

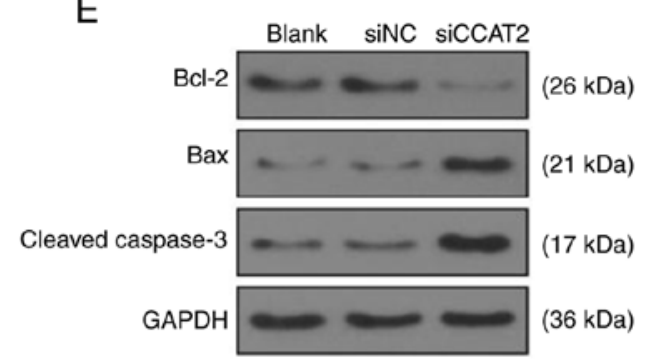

G
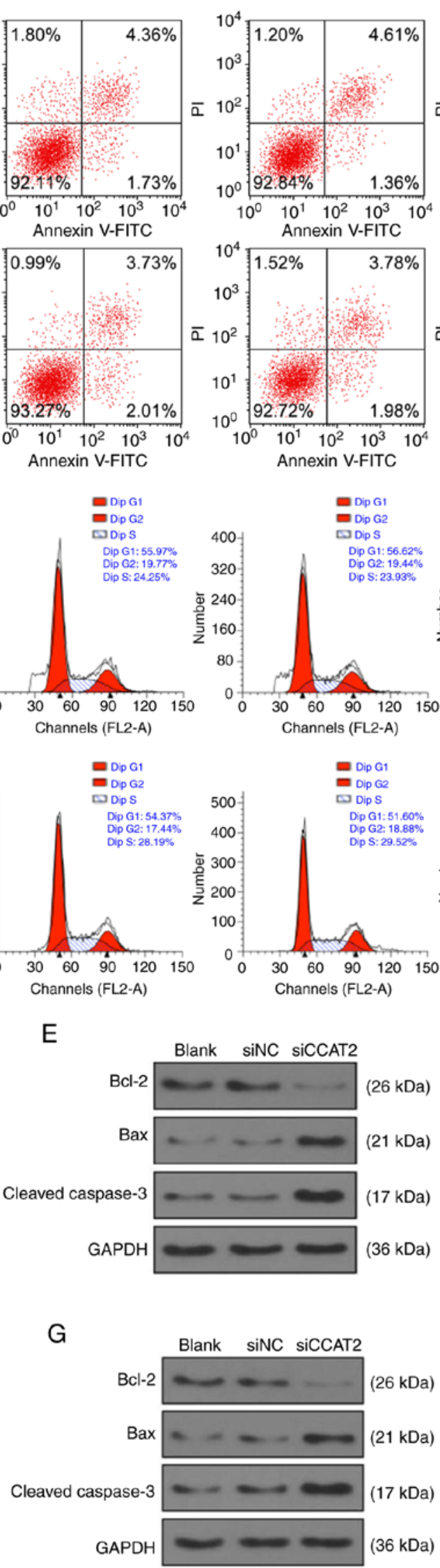
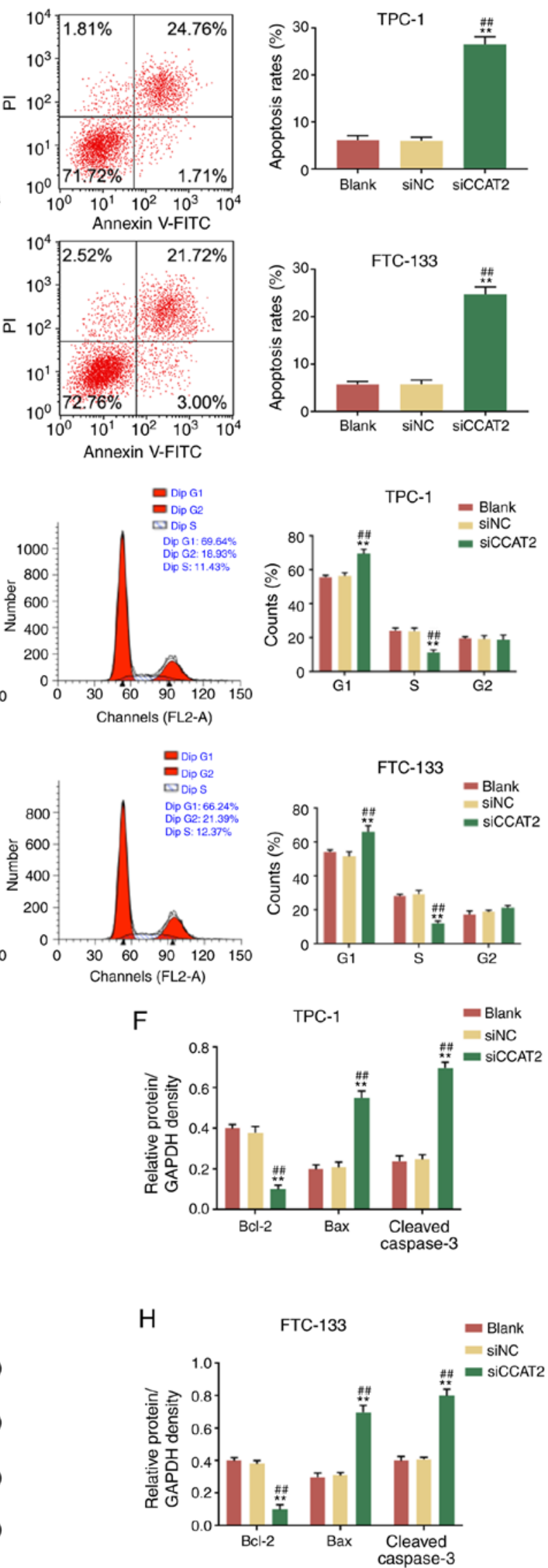

Figure 3. CCAT2 silencing promotes thyroid cancer cell cycle arrest and apoptosis. PI/Annex-V double staining followed by flow cytometry analysis was performed for si-NC or si-CCAT2 treated (A) TPC-1 and (B) FTC-133 cells to assess the cell apoptosis. After 48 h of transfection of corresponding siRNAs, the (C) TPC-1 and (D) FTC-133 cells were subjected to analysis of the cell cycle by flow cytometry. Relative protein levels of Bcl-2, Bax and C-caspase-3 were measured in (E and F) TPC-1 and (G and H) FTC-133 cells of the blank, si-NC and si-CCAT2 groups by western blotting. ${ }^{* *} \mathrm{P}<0.01$ vs. blank; ${ }^{\# \# ~} \mathrm{P}<0.01$ vs. si-NC. si, small interfering RNA; NC, negative control; PI, propidium iodide; C-caspase-3, cleaved caspase-3. 
A
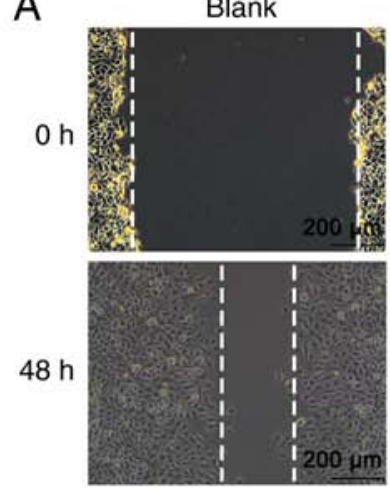

B
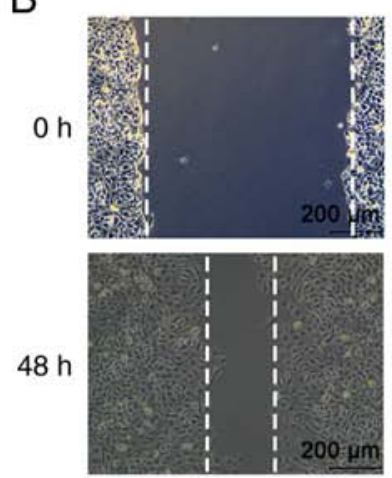

C

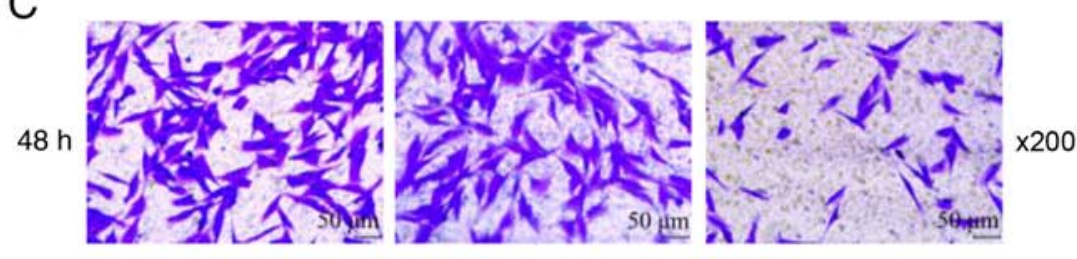

D

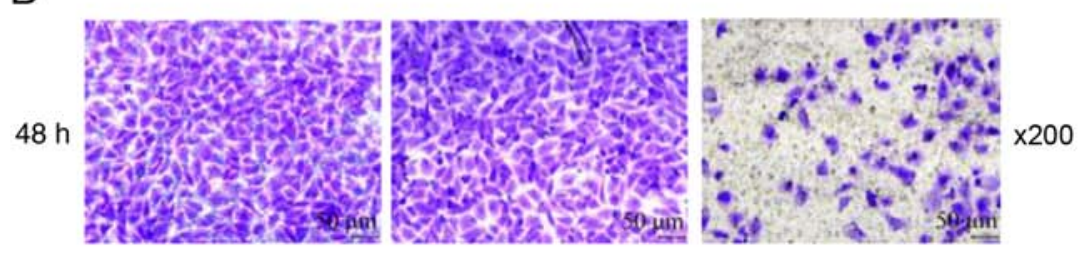

siNC
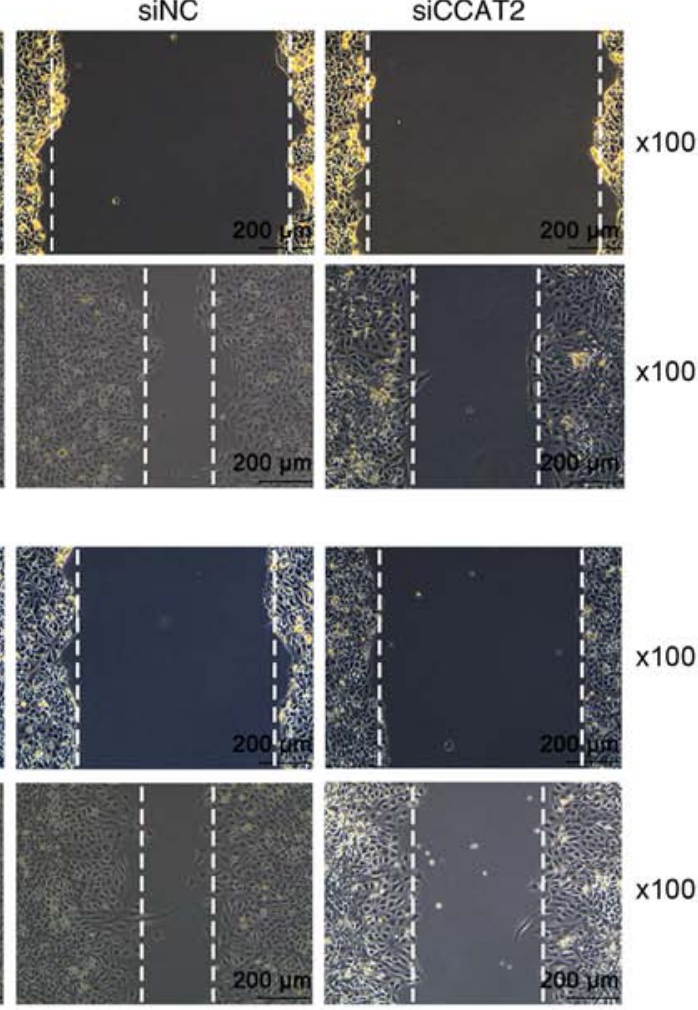
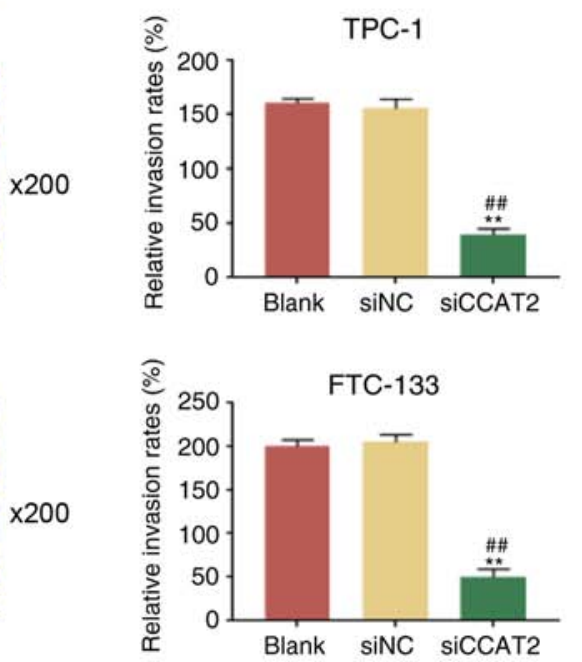

Figure 4. CCAT2 silencing suppresses thyroid cancer cell migration and invasion. Effects of si-NC and si-CCAT2 on cell migration of (A) TPC-1 and (B) FTC-133 cells were detected by wound healing assay. Effects of si-NC and si-CCAT2 on (C) TPC-1 and (D) FTC-133 cell invasion were assessed by Transwell assay. ${ }^{* *} \mathrm{P}<0.01$ vs. blank; ${ }^{\#} \mathrm{P}<0.01$ vs. si-NC. si, small interfering RNA; NC, negative control.

Previous studies have also shown that CCAT2 is involved in the progression of multiple human cancers through regulating the $\mathrm{Wnt} / \beta$-catenin signaling pathway $(21,22)$. Thus, whether the Wnt/ $\beta$-catenin signaling pathway is involved in the biological functions of CCAT2 in TC was examined. Dual-luciferase reporter assay demonstrated that the luciferase activities of the TCF/LEF reporter-TPC-1 and -FTC-133 cells treated with $\mathrm{LiCl}(10 \mathrm{nM}$, agonist of $\mathrm{Wnt} / \beta$-catenin signaling pathway) were significantly increased compared with untreated cells, but the effects could be partially reversed by the transfection of si-CCAT2 (Fig. 5A and B). In addition, the expression levels of several $\mathrm{Wnt} / \beta$-catenin cascade-associated proteins, including $\beta$-catenin, c-Myc and Cyclin D1, were detected in the CCAT2-slicenced TPC-1 and FTC-133 cells.
No significant alteration of total $\beta$-catenin was observed in the blank, si-NC and si-CCAT2 groups for TPC-1 (Fig. 5C and D) and FTC-133 cells (Fig. 5E and F). Compared with the blank group and si-NC group, si-CCAT2 transfection significantly reduced the expression levels of c-Myc and Cyclin D1, and significantly increased the expression of cytoplasmic $\beta$-catenin in TPC-1 (Fig. 5C and D) and FTC-133 cells (Fig. 5E and F). In addition, it was identified that nuclear $\beta$-catenin expression was significantly reduced in si-CCAT2 transfected TPC-1 (Fig. 5G and H) and FTC-133 cells (Fig. 5I and J) compared with the blank and si-NC groups. Histon 3 was used as an internal control. Taken together, CCAT2 knockdown significantly inhibited the $\mathrm{Wnt} / \beta$-catenin signaling pathway in TC cells. 
A
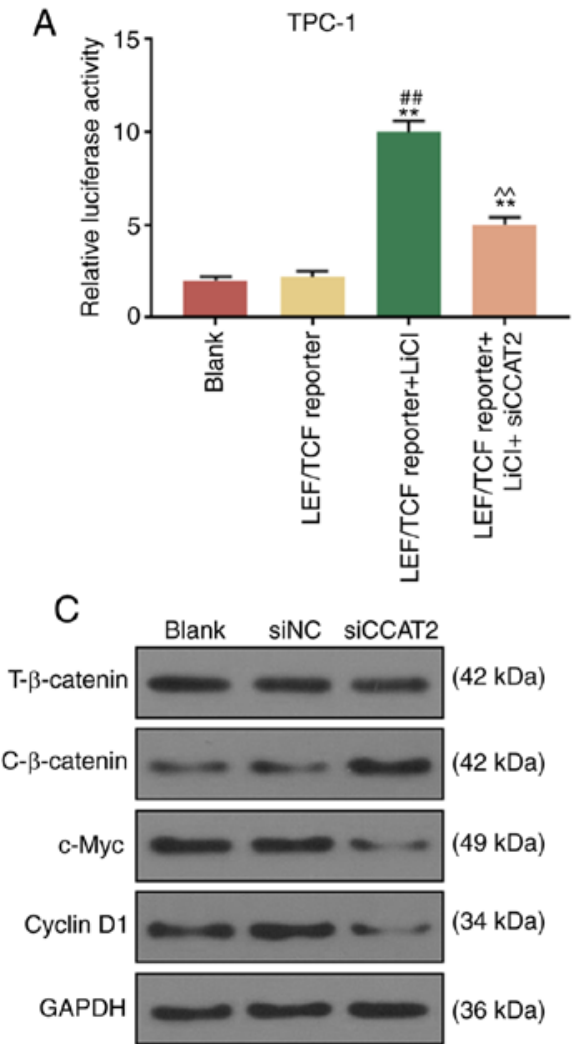

E

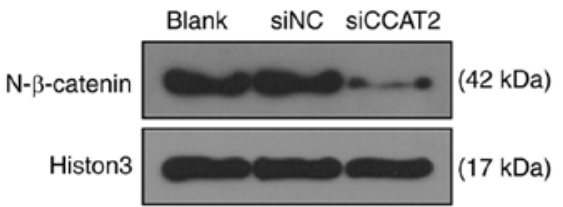

G
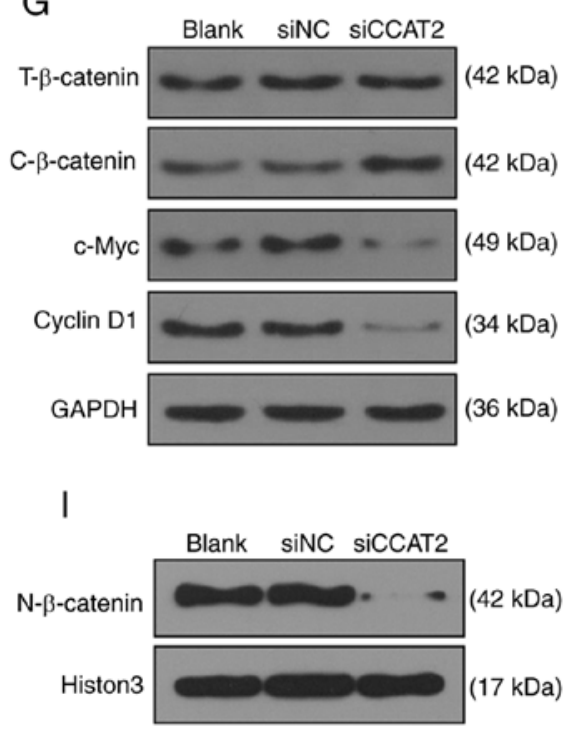

B

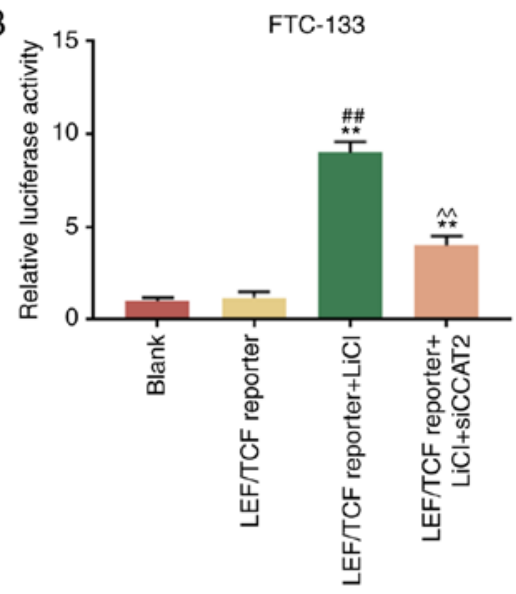

D

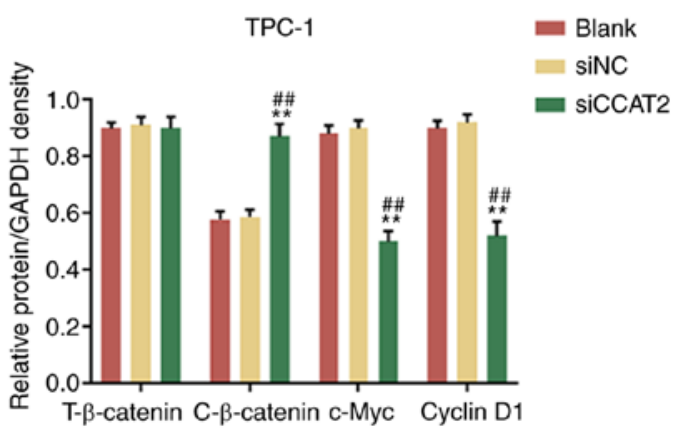

$\mathrm{F}$

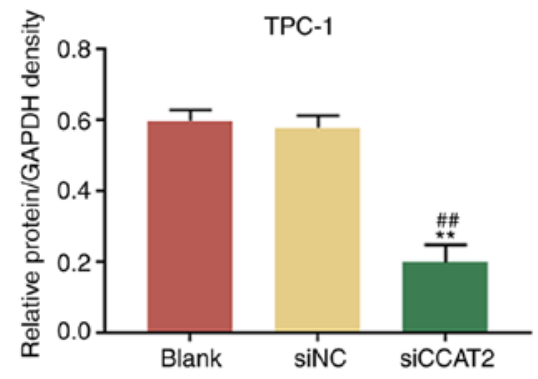

$\mathrm{H}$

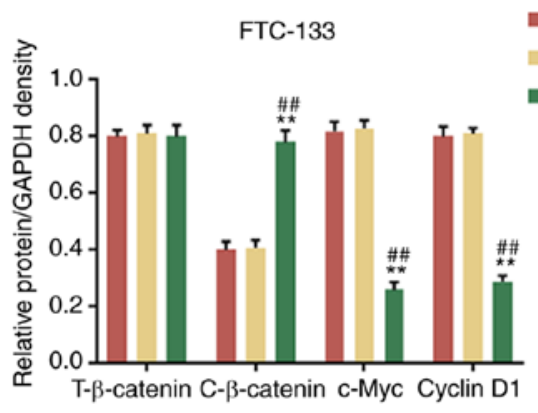

$J$

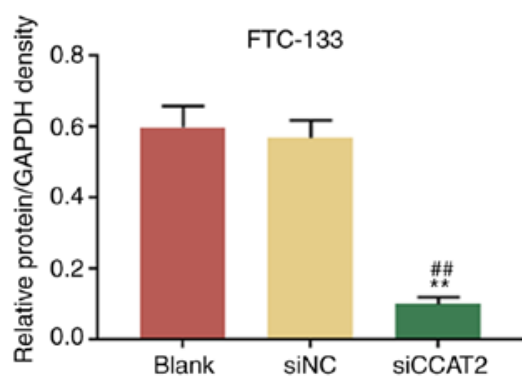

Figure 5. CCAT2 inhibits the Wnt/ $\beta$-catenin signaling pathway of thyroid cancer cells. Relative luciferase activities of (A) TPC-1 and (B) FTC-133 cells treated with LiCI and transfected with si-CCAT2 in the presence of LEF/TCF reporter were determined. ${ }^{* *} \mathrm{P}<0.01 \mathrm{vs}$. blank; ${ }^{\# \prime} \mathrm{P}<0.01 \mathrm{vs}$. LEF/TCF reporter. (C-F) Effects of si-CCAT2 on the protein relative density of T- $\beta$-catenin, C- $\beta$-catenin, c-Myc, Cyclin D1 and N- $\beta$-catenin were assessed in TPC-1 cells by western blotting. (G-J) Effects of si-CCAT2 on the protein relative density of T- $\beta$-catenin, C- $\beta$-catenin, c-Myc, Cyclin D1 and N- $\beta$-catenin were assessed in FTC-133 cells by western blotting. " $\mathrm{P}<0.01$ vs. blank; ${ }^{\# \#} \mathrm{P}<0.01$ vs. si-NC. si, small interfering RNA; NC, negative control; T, total; $\mathrm{C}$, cytoplasmic; $\mathrm{N}$, nuclear; LEF, lymphoid enhancer binding factor; TCF, transcription factor. 


\section{Discussion}

In the present study, CCAT2 expression was increased in the TC tissue samples and cell lines compared with the controls, suggesting that it may be involved in the tumorigenesis of TC. However, in the present study the samples size were relatively small, the genotype of the tumors (i.e. the presence of BRAF or ras mutations) and the radioiodine refractory tumors were not recorded, which may be limitations. To determine the function of CCAT2 in TC, the proliferation, apoptosis, cell cycle, migration and invasion of the CCAT2-silenced TC cells in vitro were detected. The results indicated that CCAT2 knockdown suppressed TC progression. In addition, the $\mathrm{Wnt} / \beta$-catenin cascade was inhibited in CCAT2-silenced TC cells, suggesting that the Wnt/ $\beta$-catenin signaling pathway might act as a downstream pathway of CCAT2 in TC. In conclusion, CCAT2 knockdown suppressed TC progression through inhibiting $\mathrm{Wnt} / \beta$-catenin signaling pathway.

Understanding of the molecular mechanisms of TC is essential to the development of effective therapeutic treatments for patients with TC. LncRNAs have increasingly been found to serve a role in the regulation of tumor progression of TC in recent years (23). Numerous IncRNAs are dysregulated in TC, which allows them to serve as diagnostic and therapeutic targets for TC $(23,24)$. However, restricted by a number of factors, there are very few lncRNAs that can be used for clinical detection of TC. CCAT2 is located on chromosome 8q24.21 (25), and its genomic locus contains a SNP rs6983267, which has been revealed to be closely associated with the increased risks of developing malignancies such as colon cancer, osteosarcoma and cholangiocarcinoma (26). Similarly, the present findings indicated that CCAT2 acts as an oncogene of TC, because the proliferation, cell cycle, migration and invasion of the TC cells with CCAT2 silencing were inhibited and the cell apoptosis was increased, indicating that CCAT2 plays an important role in tumor progression.

Bcl-2, Bax, and Caspase-3 are apoptosis-related genes, and c-Myc and cyclin D1 are involved in cell cycle progression (27). In the Bcl-2 family, Bax promotes apoptosis and Bcl-2 inhibits apoptosis $(28,29)$. Caspases will be activated before exerting their effects on cell apoptosis (30). Cyclin D1 is an important checkpoint regulator factor during the transition from the G1 to S phase (31). The present study found that the mechanism through which CCAT2 induces the inhibition of TC cell apoptosis involved decreased activation of caspase cascades and Bax, and increased activation of Bcl-2.

Wnt/ $\beta$-catenin is a highly conserved signaling pathway involved in the development of an embryo, maintenance of homeostasis and certain human diseases (32). Abnormal activation of the Wnt/ $\beta$-catenin signaling pathway can not only result in a rapid accumulation of $\beta$-catenin in the cell nucleus, thereby facilitating the transcription of a wide range of oncogenes $(32,33)$, but can also induce the tumorigenesis of multiple human cancers, including TC $(33,34)$. CircRNA_102171 silencing suppresses the proliferation, migration and invasion of PTC cells and promotes apoptosis via regulating the Wnt/ $\beta$-catenin pathway (35). The association between different lncRNAs and the Wnt/ $\beta$-catenin signaling pathway in cancer cells is widely acknowledged $(21,22,36,37)$. Zhao et al (21) found that CCAT 2 could facilitate the occurrence of non-small lung cancer through activating the Wnt/ $\beta$-catenin cascade. Ma et al (22) revealed that knocking down CCAT2 suppresses the malignancy of oral squamous cell carcinoma through inhibiting the Wnt pathway. The present study demonstrated that $\mathrm{LiCl}$ (a Wnt pathway activator) enhanced the luciferase activity of TC cells transfected with a LEF/TCF reporter plasmid, which was partially reversed by si-CCAT2. Taken together, CCAT2 could promote TC progression through activating the $\mathrm{Wnt} / \beta$-catenin cascade.

It should be noted that there were certain limitations of the current study. For example, we did examine other molecular mechanisms including the MAPK pathway, and droplet digital PCR was not performed to further support the results of RT-qPCR, which will be studied in our future research.

In conclusion, the current study demonstrated that CCAT2 acts as an oncogene of TC; knocking down CCAT2 suppressed the proliferation, migration and invasion of TC cells partially by inhibiting the Wnt $/ \beta$-catenin cascade. Thus, CCAT 2 has the potential to be used as a promising therapeutic target of TC.

\section{Acknowledgements}

Not applicable.

\section{Funding}

No funding was received.

\section{Availability of data and materials}

The datasets used and/or analyzed during the current study are available from the corresponding author on reasonable request.

\section{Authors' contributions}

SX and XY substantially contributed to the conception and design of the study, acquired, analyzed and interpreted the data, and drafted the article and critically revised it for important intellectual content. All authors read and approved the final manuscript.

\section{Ethics approval and consent to participate}

All procedures performed in studies involving human participants were in accordance with the ethical standards of the institutional and/or national research committee and with the 1964 Helsinki declaration and its later amendments or comparable ethical standards. Written informed consent was obtained from all the patients and the experiment in the study was approved by the Ethics Committee of the Changzhou Second People's Hospital Affiliated to Nanjing Medical University (approval no. NK2013100101).

\section{Patient consent for publication}

Not applicable.

\section{Competing interests}

The authors declare that they have no competing interests. 


\section{References}

1. Siegel RL, Miller KD and Jemal A: Cancer statistics, 2017. CA Cancer J Clin 67: 7-30, 2017.

2. La Vecchia C, Malvezzi M, Bosetti C, Garavello W, Bertuccio P, Levi $\mathrm{F}$ and Negri E: Thyroid cancer mortality and incidence: A global overview. Int J Cancer 136: 2187-2195, 2015.

3. Siegel RL, Miller KD and Jemal A: Cancer statistics, 2019. CA Cancer J Clin 69: 7-34, 2019.

4. Yang L, Zheng RS, Wang N, Zeng HM, Yuan YN, Zhang SW, Li HC, Liu S, Chen WQ and He J: Analysis of incidence and mortality of thyroid cancer in China, 2013. Zhonghua Zhong Liu Za Zhi 39: 862-867, 2017 (In Chinese).

5. Baloch ZW and LiVolsi VA: Special types of thyroid carcinoma. Histopathology 72: 40-52, 2018.

6. Azar FK, Lee SL and Rosen JE: Medullary thyroid cancer: An update for surgeons. Am Surg 81: 1-8, 2015.

7. Massimino M, Evans DB, Podda M, Spinelli C, Collini P, Pizzi N and Bleyer A: Thyroid cancer in adolescents and young adults. Pediatr Blood Cancer 65: e27025, 2018.

8. Raue F and Frank-Raue K: Thyroid cancer: Risk-stratified management and individualized therapy. Clin Cancer Res 22 5012-5021, 2016

9. Liu S, Liu X, Li J, Zhou H, Carr MJ, Zhang Z and Shi W: Long noncoding RNAs: Novel regulators of virus-host interactions. Rev Med Virol 29: e2046, 2019.

10. Liz $\mathrm{J}$ and Esteller M: lncRNAs and microRNAs with a role in cancer development. Biochim Biophys Acta 1859: 169-176, 2016.

11. Sui F, Ji M and Hou P: Long non-coding RNAs in thyroid cancer: Biological functions and clinical significance. Mol Cell Endocrinol 469: 11-22, 2018.

12. Gugnoni $\mathrm{M}$ and Ciarrocchi A: Long noncoding RNA and epithelial mesenchymal transition in cancer. Int J Mol Sci 20: 1924, 2019.

13. Lee KT, Gopalan V and Lam AK: Roles of long-non-coding RNAs in cancer therapy through the PI3K/Akt signalling pathway. Histol Histopathol 34: 593-609, 2019.

14. Fu D, Zhang Y and Cui H: Long noncoding RNA CCAT2 is activated by E2F1 and exerts oncogenic properties by interacting with PTTG1 in pituitary adenomas. Am J Cancer Res 8: 245-255, 2018

15. Ruan $\mathrm{R}$ and Zhao XL: LncRNA CCAT2 enhances cell proliferation via GSK $3 \beta / \beta$-catenin signaling pathway in human osteosarcoma. Eur Rev Med Pharmacol Sci 22: 2978-2984, 2018

16. Fosselteder J, Calin GA and Pichler M: Long non-coding RNA CCAT2 as a therapeutic target in colorectal cancer. Expert Opin Ther Targets 22: 973-976, 2018.

17. Miao S, Jing M, Sheng R, Cui D, Lu S, Zhang X, Jing S, Zhang X, Shan T, Shan $\mathrm{H}$, et al: The analysis of differential diagnosis of benign and malignant thyroid nodules based on ultrasound reports. Gland surgery 9: 653-660, 2020.

18. Lee H, Lee M, Byun SS, Lee SE and Hong SK: Evaluation of prostate cancer stage groups updated in the 8th edition of the American Joint Committee on cancer tumor-node-metastasis staging manual. Clin Genitourin Cancer 17: e221-e226, 2019.

19. Livak KJ and Schmittgen TD: Analysis of relative gene expression data using real-time quantitative PCR and the 2(-Delta Delta C(T)) method. Methods 25: 402-408, 2001

20. Srivastava NS and Srivastava RAK: Curcumin and quercetin synergistically inhibit cancer cell proliferation in multiple cancer cells and modulate Wnt/ $\beta$-catenin signaling and apoptotic pathways in A375 cells. Phytomedicine 52: 117-128, 2019.

21. Zhao C, Qiao C, Zong L and Chen Y: Long non-coding RNA-CCAT2 promotes the occurrence of non-small cell lung cancer by regulating the $\mathrm{Wnt} / \beta$-catenin signaling pathway. Oncol Lett 16: 4600-4606, 2018.
22. Ma Y, Hu X, Shang C, Zhong M and Guo Y: Silencing of long non-coding RNA CCAT2 depressed malignancy of oral squamous cell carcinoma via Wnt/ $\beta$-catenin pathway. Tumour Biol 39: 1010428317717670, 2017.

23. Murugan AK, Munirajan AK and Alzahrani AS: Long noncoding RNAs: Emerging players in thyroid cancer pathogenesis. Endocr Relat Cancer 25: R59-R82, 2018.

24. Zhang R, Hardin H, Chen J, Guo Z and Lloyd RV: Non-coding RNAs in thyroid cancer. Endocr Pathol 27: 12-20, 2016.

25. Xin Y, Li Z, Zheng H, Chan MTV and Ka Kei Wu W: CCAT2: A novel oncogenic long non-coding RNA in human cancers. Cell Prolif 50: e12342, 2017.

26. Ling H, Spizzo R, Atlasi Y, Nicoloso M, Shimizu M, Redis RS, Nishida N, Gafà R, Song J, Guo Z, et al: CCAT2, a novel noncoding RNA mapping to $8 \mathrm{q} 24$, underlies metastatic progression and chromosomal instability in colon cancer. Genome Res 23: 1446-1461, 2013.

27. Jo S, Ha TK, Han SH, Kim ME, Jung I, Lee HW, Bae SK and Lee JS: Myricetin induces apoptosis of human anaplastic thyroid cancer cells via mitochondria dysfunction. Anticancer Res 37: 1705-1710, 2017.

28. Tirapelli DPDC, Lustosa IL, Menezes SB, Franco IM, Rodrigues AR, Peria FM, Marinho AMDN, Serafini LN, Carlotti CG Jr and Tirapelli LF: High expression of XIAP and Bcl-2 may inhibit programmed cell death in glioblastomas. Arq Neuropsiquiatr 75: 875-880, 2017.

29. Warren CFA, Wong-Brown MW and Bowden NA: BCL-2 family isoforms in apoptosis and cancer. Cell Death Dis 10: 177, 2019.

30. Hamivand Z, Haddadi G and Fardid R: Expression of Bax and $\mathrm{Bcl} 2$ genes in peripheral blood lymphocytes of patients with differentiated thyroid cancer. J Med Phys 43: 41-45, 2018.

31. Albasri AM, Elkablawy MA, Ansari IA and Alhujaily AS: Prognostic significance of cyclin D1 Over-expression in colorectal cancer: An experience from Madinah, Saudi Arabia. Asian Pac J Cancer Prev 20: 2471-2476, 2019.

32. Nusse R and Clevers $H$ : Wnt/ $\beta$-catenin signaling, disease, and emerging therapeutic modalities. Cell 169: 985-999, 2017.

33. Shang S, Hua F and $\mathrm{Hu} \mathrm{ZW}$ : The regulation of $\beta$-catenin activity and function in cancer: Therapeutic opportunities. Oncotarget 8: 33972-33989, 2017.

34. Krishnamurthy N and Kurzrock R: Targeting the Wnt/beta-catenin pathway in cancer: Update on effectors and inhibitors. Cancer Treat Rev 62: 50-60, 2018.

35. Bi W, Huang J, Nie C, Liu B, He G, Han J, Pang R, Ding Z, Xu J and Zhang J: CircRNA circRNA_102171 promotes papillary thyroid cancer progression through modulating CTNNBIP1-dependent activation of $\beta$-catenin pathway. J Exp Clin Cancer Res 37: 275, 2018.

36. Jing N, Huang T, Guo H, Yang J, Li M, Chen Z and Zhang Y: LncRNA CASC15 promotes colon cancer cell proliferation and metastasis by regulating the miR4310/LGR5/Wnt/ $\beta$-catenin signaling pathway. Mol Med Rep 18: 2269-2276, 2018.

37. Zarkou V, Galaras A, Giakountis A and Hatzis P: Crosstalk mechanisms between the WNT signaling pathway and long non-coding RNAs. Noncoding RNA Res 3: 42-53, 2018.

This work is licensed under a Creative Commons Attribution-NonCommercial-NoDerivatives 4.0 International (CC BY-NC-ND 4.0) License. 